\title{
A IMPORTÂNCIA DA GESTÃO DA EFICIÊNCIA NOS AGRUPAMENTOS DE ESCOLAS DO ENSINO BÁSICO E SECUNDÁRIO: UM ESTUDO DE CASO
}

\author{
Albino Lopes ${ }^{1}$ \\ Luis Barrosa ${ }^{2}$ \\ Amélia Virgínia Fonseca ${ }^{3}$ \\ José Manuel Machado ${ }^{4}$
}

\begin{abstract}
RESUMO: $O$ debate nacional acerca da gestão dos estabelecimentos de ensino básico e secundário tem estado centrado em problemas curriculares e disciplinares sem atender a questões relevantes nos domínios da eficiência.

$O$ presente texto procura trazer para o cerne do debate a necessidade de se dispor de indicadores fiáveis e facilmente interpretáveis por um conjunto vasto de atores sociais interessados na eficiência das organizações escolares.

$\mathrm{Na}$ ausência desta comparabilidade entre estabelecimentos escolares dificilmente se poderá escapar a uma captura do debate democrático por interesses meramente corporativos e ou pela questão ideológica, afastando deste os principais interessados, os pais e outros atores pertinentes da comunidade educativa envolvente.

$O$ estudo de caso que suporta a apresentação e interpretação de indicadores de gestão revela que a procura de indicadores de eficiência permite, por um lado, levantar questões pertinentes de eficácia subjacentes e por outro, ganhar os docentes e outros funcionários para uma tomada de consciência da importância da gestão dos recursos humanos disponíveis nestas organizações.
\end{abstract}

Palavras-chave: Gestão Escolar, Balanço Social, Eficiência e Eficácia.

Abstract: The national debate on the management of basic and secondary educational institutions has focused on curricular and

\footnotetext{
${ }^{1}$ Albino Lopes - Professor Catedrático Jubilado do ISCSP/ULISBOA. Email: alopes@iscsp.ulisboa.pt

${ }^{2}$ Luis Barrosa - Professor Especialista do ISCE

${ }^{3}$ Amélia Virgínia Fonseca - Professora do Ensino Básico e Secundário

${ }^{4}$ José Manuel Machado - Professor do Ensino Básico e Secundário
} 
disciplinary problems, without considering other relevant issues such as efficiency.

The present text seeks to focus the debate on the need for reliable indicators which are easily understood by the vast number of social players interested in the efficiency of school establishments.

Given the lack of comparability between schools, there is always a danger that the debate becomes dominated by interest's groups or merely focuses on ideological issues, thereby alienating key stakeholders, parents and other interested parties.

This case study, which supports the presentation and interpretation of management indicators, demonstrates that the search for efficiency measures encourages the raising of issues of efficacy, and promotes an awareness, among teachers and other staff, of the availability and importance of human resource management within school establishments.

Key words: School Management, Social Balance Sheet, Efficiency and Effectiveness

\section{INTRODUÇÃO E OBJETIVOS}

O contexto teórico em que emerge a importância da Gestão Administrativa de Recursos Humanos (GARH) coincide, no final dos anos 70, com o enfoque na Gestão Estratégica de Recursos Humanos (GERH), com particular ênfase em questões como a visão, o carisma, a cultura corporativa, a mudança organizacional, entre outros temas. A GERH ocupou até aos nossos dias o essencial da produção teórica, enquanto as dimensões da GARH, isto é, da produção de indicadores e da sua comparabilidade assim como os aspetos da socio-economia, não tiveram igual tratamento no domínio do desenvolvimento teórico e de pesquisa no terreno. Admitindo que ambas as preocupações devessem merecer um tratamento equivalente, ainda assim, a profundidade da atual crise de recursos força a admitir que a visão estratégica é claramente subsidiária da inteligência fina desenvolvida na GARH, seja qual for o tipo de organização, desde que permita a comparabilidade de dados primários em vista à sua gestão eficiente. É este um dos principais esforços que urge fazer e que se encontram em situação lacunar na generalidade dos países, como reconhecem, Galdemar, Gilles et Simon (2012). Daí que certos países tenham vindo a encomendar estudos complexos e relativamente exaustivos, quanto à gestão da eficiência, a grandes consultoras, como é o caso da Bélgica, com a McKinsey \& Company (2015). Por sua vez, a importância e o peso financeiro associado à gestão eficiente das organizações públicas de educação torna necessária a inteligência coletiva dos dados e da gestão dos mesmos de maneira a que todos possam participar no controlo efetivo de custos, incluindo o incentivo 


\section{Albino Lopes, Luís Barrosa, Amélia Virgínia Fonseca e José Manuel Machado}

a que os próprios alunos se envolvam no mesmo processo. Note-se que a participação no controlo de custos é levada a sério em diversos países altamente desenvolvidos, como no exemplo paradigmático da Noruega em que este processo é reconhecido como possuindo valor educativo por si só.

O propósito deste artigo é o de contribuir para sublinhar a importância do debate em torno da criação de um quadro de indicadores, destinado a permitir a melhoria gradual e contínua da gestão dos recursos disponíveis nas organizações escolares do país.

Este quadro de indicadores pode ser apresentado em forma de relatório do tipo Balanço Social, mas não um mero ato administrativo ou obrigação legal, no caso em que este se torne imperativo. Considerando que a gestão de recursos humanos pode ser declinada segundo quatro ângulos de apreciação, o Balanço Social constitui um instrumento de gestão que em simultâneo corresponde à Gestão Administrativa de Recursos Humanos, porquanto deverá responder a normas fixadas pela Lei e/ou liderança institucional; corresponde a orientações enquadráveis na Gestão Tática de Recursos Humanos, dado que implica fórmulas e definições conceptuais tão claras e inequívocas quanto possível; enquadra-se na Gestão Estratégica de Recursos Humanos na medida em que permite operacionalizar uma leitura das forças e das fraquezas internas e da adequação da dinâmica das práticas de gestão possibilitando a escolha de caminhos para opções de futuro; e enquadra-se, finalmente na Gestão Política de Recursos Humanos dado que permite uma visão de conjunto partilhável e geradora de comunicação coerente entre a comunidade interna e a comunidade externa que visa em conjunto, fazer de toda a organização uma realidade social de interesse para a coletividade em geral.

Quando o Balanço Social se transforma numa rotina anual suscetível de responder a este conjunto de obrigações decorrente dos quatro ângulos de visão sobre a gestão das pessoas, o documento transforma-se num instrumento indispensável ao suporte de relações sociais e laborais sãs; ao mesmo tempo que permite quantificar e relacionar progressos ou retrocessos em indicadores considerados sensíveis de acordo com uma apreciação do todo (pensado numa perspetiva de gestão global e/ou regional/local do sistema escolar) e escolher as dimensões suscetíveis de serem melhoradas.

\section{ENQUADRAMENTO}

O presente documento enquadra-se na metodologia de estudo de caso de um Agrupamento Escolar Público, situado num Município da periferia da cidade de Lisboa. Enquanto estudo de caso apresenta-se uma descrição e uma justificação dos indicadores selecionados, uma vez que não existe uma 
obrigação legal para o fazer de determinada forma. Em seguida tratam-se as questões relativas às fontes de informação consultadas, apresentando-se os respetivos dados para finalmente poderem ser lidos e discutidos à luz do enquadramento teórico, mesmo na ausência de um aspeto fundamental neste género de abordagem à gestão das pessoas, que é a comparabilidade interna dos indicadores.

Na conclusão discute-se a mais-valia deste tipo de instrumentos de gestão para a melhoria da eficiência e eficácia das escolas públicas. Ele permite que a análise e discussão dos conceitos e dos dados assentem em valores reais e se enquadrem numa avaliação objetiva. A título de limitações não podemos deixar de referir que os indicadores escolhidos representam uma opção e um ensaio de instrumento a melhorar a partir da crítica interna que dela possa ser feita pelos interessados da organização e externamente pela autarquia, Conselho Geral e comunidade académica, dado que se pretende proceder a uma publicação do mesmo relatório, mantendo a necessária confidencialidade.

Este Balanço Social encontra-se dividido em oito dimensões: Emprego; Remunerações e Ação Social; Higiene e Segurança; Habilitações e Formação Profissional; Relações de Trabalho; Tempo e Trabalho; Produtividade e Disfuncionamentos, que se enquadram nas duas grandes dimensões Gestão Social e Atividade, produtividade e Disfuncionamento. Por fim apresentam-se as dimensões, as fórmulas de cálculo e respetivos valores encontrados.

\section{BASE TEÓRICA DA DEFINIÇÃO DE CONCEITOS}

A análise de uma organização através do Balanço Social pode ser observada sob duas grandes dimensões: a gestão social e a atividade, produtividade e disfuncionamento. Na primeira dimensão englobamos emprego, remunerações e ação social, higiene e segurança, habilitações e formação profissional e relações de trabalho. Na segunda englobamos tempo e trabalho, produtividade e disfuncionamentos. Cada uma destas subdimensões é analisada através dos indicadores abaixo descritos e selecionados de acordo com a especificidade da organização escolar.

\subsection{Gestão Social}

\section{Emprego}

Nível etário médio: este indicador exprime a idade média do efetivo total da organização no final do ano em análise. Uma idade média elevada teoricamente, acima dos 40 anos - pode pesar no envelhecimento da estrutura humana da organização 


\section{Albino Lopes, Luís Barrosa, Amélia Virgínia Fonseca e José Manuel Machado}

Nível de antiguidade média: Este indicador exprime o número médio de anos de casa do efetivo total da organização no final do ano em análise. $\mathrm{O}$ valor deste indicador deve ser relacionado com o número de anos de existência da organização.

Taxa de emprego de jovens: Este indicador expressa o número de trabalhadores jovens (até 25 anos de idade) por cada 100 trabalhadores do efetivo total da organização. $\mathrm{O}$ valor deste indicador evidencia, de algum modo a existência ou não de uma gestão planificada dos Recursos Humanos que atenda à estratégia de desenvolvimento da organização.

Taxa de emprego feminino: Este indicador mede o número efetivo de pessoal feminino, por cada 100 trabalhadores do efetivo total da organização. Uma taxa igual a 50 traduz uma distribuição de igualdade de postos de trabalho por homens e mulheres.

Taxa de emprego de deficientes: Este indicador mede o número de trabalhadores deficientes empregados por cada cem trabalhadores do efetivo total da organização. Quanto mais elevada for a percentagem deste indicador maior será o impacte social da organização para minimizar o mercado dos trabalhadores deficientes.

Taxa de emprego de chefias diretas: Este indicador mede o número de chefias diretas por cada 100 trabalhadores do efetivo total da organização. Admitindo como princípio geral uma relação média de um chefe para 15 operacionais, o valor teórico deste indicador situa-se à volta de 7 , número que poderá baixar em atividades de rotina e subir naquelas que requeiram maior envolvimento direto das chefias. Nesta análise consideramos os Diretores de Turma como uma chefia direta, na medida em que coordena o Conselho de Turma e é o interlocutor com os Encarregados de Educação.

Taxa de emprego de profissionais qualificados: Este indicador mede o número de trabalhadores com qualificação profissional (altamente qualificados e qualificados, por cada 100 do efetivo total da organização. Uma taxa superior a 50 revela um saldo positivo de qualificação da estrutura humana da organização.

Relação quadros médios administrativos/quadros médios operacionais: Este indicador relaciona o número de quadros médios administrativos (assistentes técnicos assistentes operacionais) com o número de quadros médios operacionais (pessoal com função docente) empregues pela organização. $\mathrm{O}$ valor superior a 1 revela excesso de técnicos com funções administrativas, relativamente ao efetivo de técnicos operando na atividade básica da organização.

Taxa de trabalhadores a prazo: Este indicador mede o número médio de trabalhadores com contrato a prazo, por cada 100 do efetivo médio da 
organização no ano em análise. Teoricamente, quanto mais elevado o seu valor maior será o nível de precariedade do trabalho na organização.

Taxa de cobertura: Este indicador mostra em que medida as entradas de pessoal compensaram as saídas ocorridas durante o ano. Uma percentagem inferior a 100 traduz uma redução do número de postos de trabalho relativamente aos efetivos no início do exercício.

\section{Remuneracõos e Ação Social}

Remuneração Base Ilíquida ${ }^{5}$ média em euros $(€)$ : Este indicador exprime a média do vencimento ilíquido base por trabalhador (euros/pessoa) praticado pela organização durante $\mathrm{o}$ ano em análise. $\mathrm{O}$ valor observado deve ser comparado com a média da tabela salarial do instrumento de regulamentação colectiva em vigor, por forma a evidenciar em que medida a organização está a pagar, ou não, acima dessa tabela.

Remuneração Base Líquida ${ }^{\mathbf{6}}$ média em euros (€): Este indicador exprime a média do vencimento líquido base por trabalhador (euros/pessoa) praticado pela organização durante o ano em análise.

No estudo em referência foi calculado o valor destes dois indicadores para o efetivo global e por categoria profissional (docentes e não docentes).

Leque de Remuneração Base Líquida: Este indicador relaciona o maior com o menor vencimento base líquido (de desconto) recebidos pelos trabalhadores. É um valor de referência para avaliação do equilíbrio das remunerações base praticadas na organização.

Leque de Remuneração Base Ilíquida: Este indicador relaciona o maior com o menor vencimento base ilíquido pago pelo Agrupamento. É, à semelhança do indicador anterior, um valor de referência para avaliação do equilíbrio das remunerações base praticadas na organização.

\section{Higiene e Segurança}

Taxa de Absentismo por doença: Este indicador mede o número de horas de ausência devidas a doença, por cada 100 horas potencialmente trabalháveis durante o ano. Teoricamente, uma percentagem reduzida reflete a eficácia da cobertura da organização na saúde e medicina do trabalho.

No caso em estudo este indicador foi calculado tendo em atenção a especificidade da função docente, isto é, foi considerado o horário sem reduções (40 horas semanais das quais 22 são de componente letiva) e posteriormente com as reduções da componente letiva, isto é, as horas

\footnotetext{
${ }^{5}$ Nesta rúbrica está incluído o subsídio de almoço, para todos, no valor mensal de 93,94€, vezes 11 meses.

${ }^{6}$ Ibidem
} 


\section{Albino Lopes, Luís Barrosa, Amélia Virgínia Fonseca e José Manuel Machado}

efetivamente lecionadas por cada docente dos $2^{\circ}$ e $3^{\circ}$ ciclo e do ensino secundário uma vez que os docentes do $1^{\circ}$ ciclo e do pré-escolar não beneficiam de reduções na componente letiva lecionando 25 horas semanais. O mesmo cálculo será feito de forma sistemática para indicadores semelhantes, exemplo Taxa de Presença.

\section{Habilitaç̃os escolares e Formação Profissional}

Taxa de Habilitação Escolar igual ou inferior ao $9^{\circ}$ ano: Este indicador mede o número de trabalhadores sem habilitação de base (iletrados ou com habilitações inferiores ao $9^{\circ}$ ano), por cada 100 trabalhadores do efetivo total da organização. Uma taxa elevada reflete um nível baixo de educação escolar do quadro de pessoal da organização

Taxa de Habilitação Secundária e Média Superior: Este indicador mede o número de trabalhadores com habilitações acima do ensino básico (secundário e médio-superior), por cada 100 trabalhadores do efetivo total da organização. Quanto mais elevado o seu valor, maior o nível de educação escolar da estrutura da organização.

Taxa de Habilitação Universitária: Este indicador mede o número de empregados com grau de licenciatura ou superior, por cada 100 trabalhadores do efetivo total da organização. A expressão deste indicador complementa a informação fornecida pelo indicador 08 (profissionais qualificados).

Taxa de Formação Profissional: Este indicador mede o número de euros despendidos em formação do pessoal, por cada 100 euros de massa salarial da organização. Quanto maior o seu valor, mais significativa a atenção que a organização atribui à formação profissional do seu pessoal.

Taxa Geral de Participação: Este indicador mede o número de trabalhadores abrangidos por ações de formação, por cada 100 trabalhadores do efetivo médio da empresa. Quanto mais elevado aquele número, maior a amplitude da formação realizada.

\section{Relacões de Trabalho}

Taxa de Sindicalização: Este indicador mede o número de trabalhadores sindicalizados, por cada 100 do efetivo total da organização. Um valor próximo de 100 traduz um sentido elevado de "classe profissional" dos trabalhadores da organização.

Este indicador também foi analisado por grupo profissional, docentes e não docentes.

Taxa de Greve: Este indicador mede o número de horas de trabalho perdidas em resultado de greves, por cada 1.000 horas potencialmente 
trabalháveis no ano em análise. Teoricamente, quanto mais elevada essa permilagem, maior o grau de conflito nas relações laborais da organização. Taxa de Frequência de Ação Disciplinar: Este indicador mede o número de processos disciplinares instaurados durante o ano em análise, por cada 100 trabalhadores do efetivo médio da organização nesse ano. Teoricamente, quanto mais elevada for essa taxa, maior a indisciplina nas relações laborais.

\subsection{Atividade, Produtividade e Disfuncionamentos}

\section{Tempo e Trabalho}

Potencial Máximo Anual Médio do Tempo de Trabalho (Horas): Este indicador exprime o número médio anual de horas de trabalho potencial por trabalhador, com base no período normal de trabalho em vigor, fixado por lei ou instrumento de regulamentação coletiva, ou por normas e usos na organização.

Taxa de Presença: Este indicador mede o número de horas efetivamente trabalhadas ao longo do ano (horas totais correspondentes ao período normal de trabalho e outras horas trabalhadas em adição a esse período), por cada 100 horas do potencial máximo anual. Uma percentagem superior a 100 indica a realização de trabalho suplementar superior aos tempos improdutivos.

Custo médio aluno sobre o total de custos conhecidos (custos de funcionamento): Este indicador mede os custos globais conhecidos efetuados ao logo do ano vs. número total de alunos. Para uma análise efetiva e que permita tirar ilações com base no valor deste indicador seria necessário confrontá-lo com valores obtidos noutros agrupamentos.

Custo médio aluno sobre a totalidade dos custos conhecidos + Custos estimados: Este indicador mede os custos globais conhecidos acrescidos de um valor de $30 \%$, referente a custos estimados para a estrutura (onde se incluem o terreno, edifício e parte da gestão do Ministério), vs. número total de alunos. O custo médio por aluno nos estabelecimentos de educação e ensino do MEC, no ano letivo de 2009/2010, segundo o Relatório N. ${ }^{\circ}$ $31 / 2012$ do Tribunal de contas, ascende a 4.415,45€, sendo o custo médio relativo ao $1 .{ }^{\circ} \mathrm{CEB}$ é de $2.771,97 €$ e o correspondente aos $2 .^{\circ}$ e $3 .{ }^{\circ} \mathrm{CEB}$ e ensino secundário é de 4.921,44€.

Custo médio por turma: Este indicador mede os custos globais por turma/ano.

Custo médio por turma + custos de estrutura estimados: Este indicador mede os custos globais por turma/ano, incluindo custos de estrutura estimados e calculados de forma idêntica à utilizada no indicador 'custo médio aluno sobre a totalidade dos custos conhecidos + Custos estimados'. 


\section{Albino Lopes, Luís Barrosa, Amélia Virgínia Fonseca e José Manuel Machado}

Rácio professor/aluno: Este indicador mede o número médio de alunos por professor.

Rácio assistentes operacionais/alunos: Este indicador mede o $\mathrm{n}^{\circ}$ médio de alunos por assistente operacional.

\section{Produtividade}

Retribuição Média Anual (Euros): Este indicador exprime a média da retribuição anual ilíquida por trabalhador (euros/pessoa), englobando o vencimento-base, complementos e outros encargos sociais.

A análise do valor observado para este indicador permite evidenciar indiretamente o nível das remunerações complementares e outros encargos sociais concedidos pela organização.

\section{Disfuncionamentos}

Rotação do Pessoal: Este indicador mede a relação entre o efetivo final e o inicial, acrescido dos movimentos de entrada e de saída, no decurso do ano em análise. Teoricamente, o seu valor situa-se entre 0 e 1 , variando em função das condições internas da organização (categoria profissional, idade e antiguidade do efetivo) e/ou por razões externas (tensões no mercado de trabalho).

Absentismo: Este indicador mede o número de horas de ausência do trabalhador do posto de trabalho, por cada 100 horas potencialmente trabalháveis durante o ano. Esse número varia, principalmente, em razão do sector de atividade da organização e das condições de trabalho em que a mesma opera.

\section{METODOLOGIA}

O presente documento enquadra-se na metodologia de estudo de caso de um Agrupamento Escolar Público, situado num Município da periferia da Grande Lisboa. Enquanto estudo de caso apresenta-se uma descrição e uma justificação dos indicadores selecionados, uma vez que não existe uma obrigação legal para o fazer de determinada forma. Em seguida tratam-se as questões relativas às fontes de informação consultadas, apresentando-se os respetivos dados para finalmente poderem ser lidos e discutidos à luz do enquadramento teórico, mesmo na ausência de um aspeto fundamental neste género de abordagem à gestão das pessoas, que é a comparabilidade interna dos indicadores.

Dado que não são conhecidos estudos que permitem a consolidação de uma metodologia generalizável foi necessário fazer opções e escolher indicadores pertinentes remetendo para a conclusão uma apreciação crítica 
dos mesmos. Deste modo na conclusão discute-se a mais-valia deste tipo de instrumentos de gestão para a melhoria da eficiência e eficácia das escolas públicas. Ele permite que a análise e discussão dos conceitos e dos dados assentem em valores reais e se enquadrem numa avaliação objetiva. A título de limitações não podemos deixar de referir que os indicadores escolhidos representam uma opção e um ensaio de instrumento a melhorar a partir da crítica interna que dela possa ser feita pelos interessados da organização e externamente pela autarquia, Conselho Geral e comunidade académica, dado que se pretende proceder a uma publicação do mesmo relatório, mantendo a necessária confidencialidade.

Este Balanço Social encontra-se dividido em oito dimensões, como já antes referenciado e que são: Emprego; Remunerações e Ação Social; Higiene e Segurança; Habilitações e Formação Profissional; Relações de Trabalho; Tempo e Trabalho; Produtividade e Disfuncionamentos, que se enquadram nas duas grandes dimensões Gestão Social e Atividade, produtividade e Disfuncionamento.

Em seguida apresentam-se as dimensões, as fórmulas de cálculo e respetivos valores encontrados.

\section{APRESENTAÇÃO DOS DADOS}

De forma a separar dados de resultados, neste ponto explicitam-se as fórmulas que permitem produzir e enquadrar os valores relativos a cada dimensão de maneira a poderem ser replicados e confrontados de forma inequívoca em outras investigações similares.

\section{A. Gestão Social}

I - Emprego

01. Nível etário médio (Idade) - 48,3 anos

01.1 Docentes $-47,2$ anos

01.2 Não docentes $-52,9$
Soma das Idade

$\frac{\text { (7527) }}{\text { Efetivo total (156) }}$

Os valores encontrados refletem um envelhecimento da estrutura humana do Agrupamento que nos parece agravado pelo baixo valor de 8,8 anos de antiguidade no Agrupamento- indicador 02.1.

02.1 Nível de antiguidade média global no Agrupamento (Anos) - 8,8 anos:
Soma das Antiguidades (1375) 


\section{Albino Lopes, Luís Barrosa, Amélia Virgínia Fonseca e José}

Manuel Machado

02.1.1 Docentes - 6,9 anos

Efetivo total (156)

02.1.2 Não docentes -17 anos

02.2 Nível de antiguidade média global na Profissão (Anos) - 21,7 anos

02.2. 1 Docentes $-21,9$ anos 02.2. 2 Não docentes - 20,7 anos
Soma das Antiguidades

$\frac{(3075)}{\text { Efetivo total (142) }}$

Trab. até 25

$\frac{\operatorname{anos}(0)}{\text { Efetivo total }} \times 100$

(156)

No Agrupamento não existe nenhum trabalhador com menos de 25 anos.

04. Taxa de emprego feminino $=\frac{\begin{array}{l}\text { Efetivo total } \\ \text { 82,1\% } \%\end{array}}{\text { mulheres }(128)}$
Efetivo total $(156)$ 100

No Agrupamento existe um predomínio do género feminino $(82,1 \%)$

05. Taxa de emprego de deficientes $(\%)=0 \%$
Trabalhadores

$$
\frac{\text { deficientes }(0)}{\text { Efetivo total }(156)} \times 100
$$

No Agrupamento não existe nenhum trabalhador com deficiência.

06. Taxa de emprego de chefias $\operatorname{diretas}(\%)=14,1 \%$

06.1 Docentes $-15,9$ 06.2 Não docentes - 6,7
Coordenadores,

Representantes de grupo, chefes de assistentes operacionais $e$ $\frac{\text { técnicos }(22)}{\text { Efetivo total }} \times 100$ (156)

Para este indicador foram contabilizados os Coordenadores, os Representantes de Grupo, a Chefia dos Assistentes Operacionais e a Chefia de trabalhadores Administrativos. Nas chefias diretas não se consideraram os Diretores de Turma, dado estes estarem numa relação direta com o número de alunos, cálculo que fazemos a seguir. 


\subsection{Taxa de incidência de diretores de turma $(\%)=42,8 \%$ \\ Diretores de

$$
\frac{\text { turma, }(54)}{\text { Efetivo total }} \times 100
$$

A Taxa de emprego de Diretores de Turma no efetivo total do Agrupamento foi de $37,3 \%$

Prof. Alt. Qual. +

08. Taxa de emprego de profissionais $\frac{\text { Prof. Qual. (130) }}{\text { Efetivo total }} \times 100$
qualificados $(\%)=\mathbf{8 3 , 3 \%}$

Neste indicador estão incluídos os 126 docentes, os dois técnicos superiores (Psicólogos) e as chefias dos assistentes operacionais e dos assistentes técnicos.

\section{Relação quadros médios} administrativos/ quadros médios operacionais vs. pessoal com funções docentes $=\mathbf{0 . 2 4}$
Técnicos

Administrativos e

$\frac{\text { de apoio (30) }}{\text { Pessoal com }}$

funções docentes

(126)

O valor encontrado no Agrupamento foi de 0,24

$$
\begin{array}{lc}
\text { 10. Taxa de trabalhadores a prazo } & \text { Média anual } \\
(\%)=\mathbf{3 0 , 1 \%} & \frac{\text { Contra prazo }(47)}{\text { Efetivo Anual }} \times 100 \\
& \text { Médio }(156)
\end{array}
$$

Neste indicador estão incluídos os professores com contrato a termo certo e a termo incerto (47). Todo o restante pessoal tem contrato a termo indeterminado. A taxa de trabalhadores a prazo no Agrupamento é de 30,1\%

$$
\text { 11. Taxa de cobertura }(\%)=\mathbf{1 0 1 , 6 \%} \quad \frac{\text { Admissões }}{\text { Demissões }} \times 100
$$

No Agrupamento verificou-se um aumento de 1, 6\% dos postos de trabalho. 


\section{Albino Lopes, Luís Barrosa, Amélia Virgínia Fonseca e José} Manuel Machado

\section{II - Remunerações e Ação Social}

12. Remuneração Base Ilíquida ${ }^{7}$ média (€) (14 Vencimento base meses $)=3.709 .626 / 156=23.780 €$ anual ilíquido total

$$
\begin{aligned}
& \text { 12.1 Docentes }=3.382 .894 / 126= \\
& 28.848,4 € \\
& 12.2 \text { Não docentes }=326.731 / 30= \\
& 10.891,0 €
\end{aligned}
$$

$$
\frac{(3.709 .626 €)}{\text { Efetivo médio }}
$$

13. Remuneração Base Líquida ${ }^{8}$ média $(€)(14$ meses $)=2.415 .587 / 156=15.484,7 €$

13.1 Docentes $=2.161 .800,6 / 126=17.157,1 €$

13.2 Não docentes $=263.133,8 / 30=8.771,1 €$

Vencimento base anual líquido total $\frac{(2.415 .587 €)}{\text { Efetivo médio }}$ (156)

Este indicador exprime a média do vencimento líquido base por trabalhador (euros/pessoa) praticado pela organização durante o ano em análise.
14. Leque de Remuneração Base Líquida = 3,6
Maior Venc. base

\begin{tabular}{c} 
líquido $(1611,14)$ \\
\hline Menor Venc. base \\
líquido $(443,19)$
\end{tabular}

O leque de remuneração base líquida no Agrupamento, no ano em análise, foi de 3,6

$$
\text { 15. Leque de Remuneração Base Ilíquida }=\mathbf{5 , 6} \frac{\begin{array}{c}
\text { Maior Venc. base } \\
\text { ilíquido }(2.896,07 \epsilon)
\end{array}}{\begin{array}{l}
\text { Menor Venc. base } \\
\text { ilíquido }(518,35 \epsilon)
\end{array}}
$$

Este indicador é, à semelhança do indicador anterior, um valor de referência para avaliação do equilíbrio das remunerações base praticadas no Agrupamento.

\section{III - Higiene e Segurança}

\section{1 Taxa de Absentismo por doença sem reduções de horário $(\%)$ 12,4

$\begin{gathered}\text { Horas Ausência } \\ \text { p/doença }(33828)\end{gathered}$
$\begin{gathered}\text { Potencial Máximo } \\ \text { Anual }(272 \text { 040) }\end{gathered}$

\footnotetext{
${ }^{7}$ Nesta rúbrica está incluído o subsídio de almoço, para todos, no valor mensal de 93,94€, vezes 11 meses,

${ }^{8}$ Ibidem
} 
Para o cálculo do número de horas, contabilizou-se o horário de 40 horas semanais para todos os funcionários. O valor encontrado foi de $12,4 \%$ de absentismo por doença.

\section{Horas Ausência \\ 16. 2 Taxa de Absentismo por doença com $\frac{\text { p/doença (33828) }}{\text { Potencial Máximo }} \times 100$
reduções de horário (\%) 13,5 \\ Anual (249 788)}

O valor encontrado foi de $13,5 \%$ de absentismo por doença.

Para o cálculo do número de horas foram contabilizadas 40 horas para os não docentes, incluindo o diretor, e para o pessoal docente foram consideradas as 40 horas semanais com as reduções da componente letiva, isto é, as horas efetivamente lecionadas por cada docente dos $2^{\circ}$ e $3^{\circ}$ ciclo e do ensino secundário uma vez que os docentes do $1^{\circ}$ ciclo e do pré-escolar não beneficiam de reduções na componente letiva lecionando 25 horas semanais.

\section{IV - Habilitações escolares e Formação Profissional}

$$
\begin{aligned}
& \text { 17. Taxa de Habilitação Escolar } \\
& \text { igual ou inferior ao } 9^{\circ} \text { ano }(\%) \\
& =9,6 \%
\end{aligned}
$$

18. Taxa de Habilitação Secundária e

$N^{o}$ Tr. c/Ens. Sec. e Média Superior $(\%)=8,9 \%$

$\frac{\text { Med. Sup. }(14)}{\text { Efetivo Total (156) }} \times 100$

O valor desta taxa, 8,9\% mostra o nível de educação escolar da estrutura da organização.

\section{Taxa de Habilitação Universitária $(\%)=81,4 \%$}

$$
\begin{aligned}
& N^{o} \text { trab. C/Ens. } \\
& \frac{\text { Universitário (127) }}{\text { Efetivo Total (156) }} \times 100
\end{aligned}
$$

Este indicador complementa a informação fornecida pelo indicador 08 (taxa de emprego de profissionais qualificados) e está de acordo com o tipo de organização em estudo.

$$
\text { 20. Taxa de Formação Profissional }(\%)=0 \frac{\begin{array}{c}
\text { Total Custo } \\
\text { de Formação }
\end{array}}{\text { Massa }} \times 100
$$

Não existe informação sobre este indicador. De fato, vários profissionais fizeram formação mas às suas custas e não existe registo sobre a mesma. 


$$
\text { 21. Taxa Geral de Participação }(\%)=\mathbf{0} \quad \begin{gathered}
N^{o} \text { Trab. em } \\
\frac{\text { Ações Form. }}{\text { Efetivo Anual }} \\
\text { Médio }
\end{gathered} 100
$$

Também não existe informação sobre este indicador.

\section{V-Relações de Trabalho}

$$
\begin{aligned}
& \text { 22. Taxa de Sindicalização }(\%)=\quad N^{o} \text { Trab. Sindicalizados } \\
& 14,1 \% \\
& \text { 22.1 Docentes }(\%)=8,6 \% \quad \text { Efetivo Total (156) } 100 \\
& 22.2 \text { Não docentes }(\%)= \\
& 54,5 \%
\end{aligned}
$$

Uma taxa de sindicalização de 14,1 revela a não existência de um sentido elevado de "classe profissional" dos trabalhadores do Agrupamento. É nos não docentes que o valor da taxa de sindicalização, $54 \%$ tem significado para o funcionamento do Agrupamento.

23. Taxa de Greve (\%o) 0,9

$$
\begin{aligned}
& N^{o} \text { Horas Perd. por } \\
& \frac{\text { Greve }(230,4)}{\text { Potencial Máximo Anual }} \times 10^{3}
\end{aligned}
$$

(272 040)

O valor de $0,9 \%$ mostra um baixo grau de conflito nas relações laborais no Agrupamento.

\section{Taxa de Frequência de Ação Disciplinar 0\%}

$$
N^{o} \text { Proces. Instaur. no }
$$$$
\frac{\text { ano (0) }}{\text { Efetivo Médio Anual }} \times 100
$$$$
\text { (156) }
$$

Este indicador revela a não existência de indisciplina nas relações laborais no Agrupamento.

\section{B. Atividade, produtividade e disfuncionamentos}

VI - Tempo e Trabalho

25.1 Potencial Máximo Anual Médio do Tempo de Trabalho (Horas) Sem redução - 1743,9
Potencial Máximo Anual (272 040)

Efetivo Anual Médio (156) 
25.2 Potencial Máximo Anual

Médio do Tempo de Trabalho

(Horas) Com redução - 1594,8
Potencial Máximo Anual (249 788)

Efetivo Anual Médio (156)

Para o cálculo destes dois indicadores, bem como da Taxa de Presença (26.1, 26.2, 34.1 e 34.2) foram usados os mesmos procedimentos que se efetuaram para calcular o absentismo por doença (16.1 e 16.2)

$$
\begin{aligned}
& \text { 26.1 Taxa de Presença s/redução (\%) } \\
& =\mathbf{8 4 , 5}
\end{aligned} \frac{N^{o} \text { Horas Trabalhadas }}{\text { Potencial Máximo Anual }} \times 100
$$

26.2 Taxa de Presença c/redução

$(\%)=83,1$

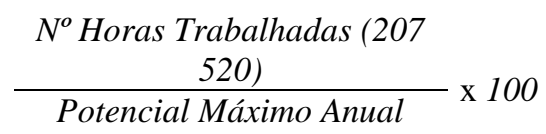

(249 788)

27. Custo médio aluno sobre o total de custos conhecidos (custos de funcionamento $)=$ 4.069,5€

Este indicador mede os custos globais conhecidos efetuados ao logo do ano vs. número total de alunos.

28. Custo médio aluno sobre a totalidade dos custos conhecidos

+ Custos estimados $=\mathbf{5 . 2 9 0 , 4 €}$
Total de custos conhecidos + Custos c estrutura estimados $(5.967 .520,2)$

$N^{\circ}$ Total de aluno (1.128)

Este indicador mede os custos globais conhecidos acrescidos de um valor de $30 \%$, referente a custos estimados para a estrutura (onde se incluem o terreno, edifício e parte da gestão do Ministério), vs. número total de alunos.

O custo médio por aluno nos estabelecimentos de educação e ensino do MEC, no ano letivo de 2009/2010, segundo o Relatório N. . 31/2012 do Tribunal de contas, ascende a 4.415,45€, sendo o custo médio relativo ao $1 .^{\circ}$ CEB é de 2.771,97€ e o correspondente aos $2 .^{\circ}$ e $3 .^{\circ}$ CEB e ensino secundário é de 4.921,44€.

29.1 Custo médio por turma $=$ 85.007,4€

Este indicador mede os custos globais por turma/ano. O número médio de alunos por turma no ano letivo 2014/2015 foi, no Agrupamento, de 21 alunos. 


\section{Albino Lopes, Luís Barrosa, Amélia Virgínia Fonseca e José Manuel Machado}

29.2 Custo médio por turma + custos de estrutura estimados $=$ $110.509,6 €$
Total de custos conhecidos + custos de estrutura estimados (5.967.520,2€)

$N^{\circ}$ Total de turmas (54)

$\mathrm{O}$ valor deste indicador revela um custo elevado por turma e deve ser analisado em conjunto com o indicador 30 .

\section{Rácio professor/aluno $=9$}

$N^{o}$ Total de alunos (1128)

$N^{o}$ total de professores (126)

Este indicador mede o número médio de alunos por professor que é excessivamente baixo. Este rácio mostra a possível existência de um número significativo de docentes sem componente letiva.

\section{Rácio assistentes operacionais/alunos $=\mathbf{5 1 , 3}$}

$\frac{N^{o} \text { Total de alunos (1128) }}{N^{o} \text { Total assistentes operacionais (22) }}$

Este indicador mede o número médio de alunos por assistente operacional.

Neste ano letivo verificou-se um reforço de 11 assistentes operacionais em contrato de emprego inserção. Estes profissionais não têm um período de tempo definido, tanto podem estra uma semana como, no máximo, um ano, dado que estão no desemprego e afetos aos respetivos Centros de Emprego. Contando com estes colaboradores o rácio passa para 34,2.

\section{VII - Produtividade}

32. Retribuição Média Anual $($ Euros $)=28.391,3 €$
VBase+Compl + out. Enc Soc. (4.429.042,75€)

Efetivo Médio (156)

$\mathrm{O}$ valor deste indicador, mostra que o valor da retribuição anual ilíquida por trabalhador (euros/pessoa), englobando o vencimento-base, complementos e outros encargos sociais é, em média, $4.611 €$ superior à remuneração base ilíquida.

\section{Disfuncionamentos}

\section{Rotação do Pessoal - 0,6}

Efectivo Final (156)

Efect. inic. + Entrad+Saídas (274)

O valor de 0,6 mostra uma elevada rotação de pessoal, facto que se verifica essencialmente, no pessoal docente. 


$$
\begin{aligned}
& \text { 34.1 Absentismo s/redução (\%) - } \frac{\text { Horas de Ausência (42 268) }}{\text { Potencial Máximo Anual (272 }} \text { 040) } \\
& \text { 15,5\% } 100
\end{aligned}
$$

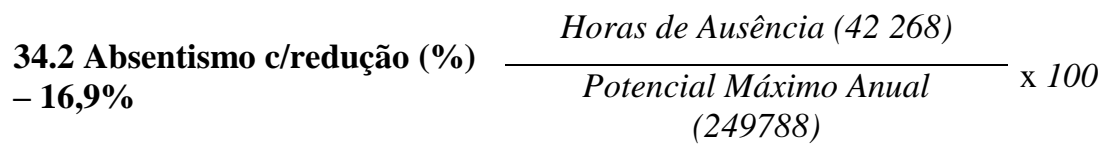

Os valores encontrados revelam um elevado absentismo e um aumento de cerca de $3 \%$ relativamente às respetivas taxas de absentismo por doença.

\section{Análise dos resultados}

O Nível etário médio dos trabalhadores do Agrupamento foi em 2015, de 48,3 anos, sendo a média do corpo docente de 47 e dos não docentes de 53 anos. Estes valores quando comparados com a média etária da população portuguesa $(43,5 \text { anos })^{9}$ e da Europa a $28(42,4)^{10}$, pode-se considerar muito elevado e com necessidade de correção urgente. O problema é que não está no âmbito da direção do agrupamento corrigir a realidade que se encontra subjacente a este indicador de gestão. O recrutamento dos docentes continua centralizado no Ministério da Educação e deixado à aleatoriedade das conveniências dos mesmos enquanto o recrutamento dos não docentes do $1^{\circ}$ ciclo vai estar na mão da Autarquia. Atualmente, não está na mão dos Agrupamentos, gerir este recurso.

A antiguidade média dos não docentes, na profissão (20,7 anos) e no agrupamento (17) estão de tal modo próximos que revelam um recrutamento já de si tardio. Nos docentes a média é relativamente afastada ( 6,9 anos no agrupamento contra 22 anos na carreira), mostrando, neste caso, que os concursos servem para os docentes se aproximarem da escola mais perto da residência. Revela mais um comprometimento com a carreira do que uma aposta na organização.

O emprego jovem é inexistente neste agrupamento, com uma taxa de $0 \%$ reforçando a ideia de que não existe gestão previsional.

A taxa de feminidade, no Agrupamento foi de $82,1 \%$, um pouco acima dos valores, no Ensino Básico e Secundário que foi de 76,7\% segundo os dados da DGEEC ${ }^{11}$.

O Artigo $71 .^{\circ}$ da Constituição Portuguesa de 1976 refere no ponto 2 que "O Estado obriga-se a realizar uma política nacional de prevenção e de

\footnotetext{
${ }^{9}$ Disponível em: http://www.pordata.pt/Europa/Popula\%C3\%A7\%C3\%A3o+residente+idade+mediana2265, consultado em 23.02.2017

${ }^{10}$ Ibidem

${ }^{11}$ DGEEC Educação em número 2012
} 


\section{Albino Lopes, Luís Barrosa, Amélia Virgínia Fonseca e José Manuel Machado}

tratamento, reabilitação e integração dos cidadãos portadores de deficiência e de apoio às suas famílias, a desenvolver uma pedagogia que sensibilize a sociedade quanto aos deveres de respeito e solidariedade para com eles e a assumir o encargo da efetiva realização dos seus direitos, sem prejuízo dos direitos e deveres dos pais ou tutores. A fim de promover a integração profissional de pessoas com deficiência no seio da Administração Pública, o Decreto-Lei 29/2001 de 3 de Fevereiro estabeleceu uma quota obrigatória para admissão no serviço público: $5 \%$ das vagas devem ser reservadas para pessoas com deficiência quando o concurso envolver 10 ou mais lugares; um lugar quando se tratar de 3 a 9 vagas, devendo ser dada preferência ao candidato com deficiência com igual classificação quando o concurso envolver 1 ou 2 lugares. Apesar desta legislação estar em vigor desde 2001, um estudo de 2006 realizado pelo Instituto Nacional de Administração (INA) revelou que a administração pública portuguesa apenas dispõe de cerca de 3.000 pessoas com deficiência, um número que corresponde a menos de $1 \%$ de todos os funcionários públicos (Anjos e Rando 2009). Destes, $40 \%$ tinham deficiências relacionadas com o diagnóstico de cancro, o que significa que já eram funcionários públicos quando adquiriram sua deficiência. $\mathrm{O}$ estudo concluiu, portanto, que a admissão de trabalhadores com deficiência na Administração Pública em Portugal tem sido residual ${ }^{12}$. O valor encontrado no Agrupamento foi de $0 \%$.

A taxa de emprego de chefias diretas ${ }^{13}$ na educação não tem a mesma tradução que na generalidade das outras atividades, pois trata-se de uma burocracia profissional em que a hierarquia é mais de tipo enquadramento/coordenação do que de tipo chefia hierárquica. $\mathrm{O}$ valor encontrado para a totalidade dos profissionais foi de $14,1 \%$, sendo nos docentes de $15,9 \%$, o que pode ser considerado como ajustado a este tipo de atividade. Nos não docentes o valor do rácio 6,7\% parece manifestamente exagerado, podendo neste caso concreto revelar dificuldades no que respeita à polivalência e à gestão por equipas.

A taxa de incidência de diretores de turma foi de $42,8 \%$. Se a este indicador somarmos outro tipo de coordenações, tais como coordenador de estabelecimento, coordenadores de grupo e coordenador pedagógico a taxa de coordenação assume valores superiores. Estes valores indiciam a necessidade de formação contínua no que respeita à liderança de equipas, competências de coordenação e de sensibilidade à gestão, em praticamente todo o corpo docente.

\footnotetext{
${ }^{12}$ Copyright 2012 Disability Rights Promotion International Portugal (DRPI-Portugal)

${ }^{13}$ Coordenadores, os Representantes de Grupo, a Chefia dos Assistentes Operacionais e a Chefia de trabalhadores Administrativos
} 
Se atendermos à tendência evolutiva da generalidade dos serviços que apontam para uma coprodução, como defendem Vargo e Lusch (2004; 2008), nesse caso os representantes de grupo e os diretores de turma deveriam constituir a estrutura mais importante dos estabelecimentos de ensino e seria aconselhável um funcionamento em matriz de forma a colocar o aluno como centro da atividade escolar. É a matriz que permite a gestão da aprendizagem de cada aluno e deveria ser a criação desta estrutura de tipo matricial o principal órgão para a análise e gestão do sucesso/insucesso e da conflitualidade.

A taxa de emprego de profissionais qualificados $83,3 \%$ está de acordo com o tipo de organização em análise.

A relação quadros médios administrativos/quadros médios operacionais vs. quadros de pessoal com funções docentes é de 0.24 , valor que se pode considerar normal para este tipo de organizações.

A taxa de trabalhadores a prazo é de $30,1 \%$ e é na classe docente que se reflete a totalidade da precaridade do trabalho nesta organização em concreto. Pode-se considerar um número bastante elevado e parece demonstrar que a gestão centralizada fomenta este género de precariedade. A taxa de cobertura foi de $101,6 \%$ refletindo um crescimento de profissionais face ao ano anterior em 1,6\%.

No capítulo das remunerações o valor médio das remunerações ilíquidas anuais (14 meses), encontrado para a totalidade do agrupamento, foi de $23.780 €$, sendo que o valor para o corpo docente foi de $28.848 €$ e para os não docentes de $10.891 €$. O leque de remuneração base ilíquida foi de 5,6. No capítulo remunerações base líquidas os valores encontrados, para o mesmo período, foram de $15.484,7 €$ no total e de $17.157,1 €$ para os docentes e de $8.771,1 €$ para os não docentes e o leque de remuneração base desce para 3,6 .

Dado que não existem dados publicados para o setor, não nos é possível evidenciar se a organização está acima ou abaixo da média. Podemos simplesmente referir que o salário médio nacional ronda os $9.800 €$ líquidos anuais.

No capítulo Higiene e Segurança o valor encontrado para a taxa de absentismo por doença foi de $12,4 \%$, o que se pode considerar um valor muitíssimo elevado. Com o valor de absentismo por doença encontrado no agrupamento, pode colocar-se a hipótese de stresse ocupacional, dada a propensão da classe docente para este tipo de doença.

No capítulo habilitações escolares os valores encontrados espelham o tipo de organização, com $81,4 \%$ de habilitações universitárias; $8,9 \%$ com habilitações secundária e média superior e 9,6\% com habilitações igual ou inferior ao $9^{\circ}$ ano. 


\section{Albino Lopes, Luís Barrosa, Amélia Virgínia Fonseca e José Manuel Machado}

Sobre a Formação Profissional não foram encontrados registos que permitam a análise deste indicador. Esta lacuna de informação reflete pouca preocupação com um dos quatro indicadores que a compõem uma Gestão Tática de Recursos Humanos. Se considerarmos que a função docente é uma das que mais carece de formação e atualização, sobretudo devido à instabilidade pedagógica e ao stresse ocupacional a que está submetida, esta rúbrica deveria merecer um particular cuidado da gestão. Não nos podemos esquecer que este campo é um dos poucos que não dependem de uma gestão centralizada. Formação deve existir, até por obrigação na avaliação de desempenho, só que é gerida por opções individuais e de aposta na própria carreira.

Nas relações de trabalho encontramos uma taxa de sindicalização global de $14,1 \%$, sendo que na classe docente é de $8,6 \%$ e nos não docentes de $54,5 \%$. O valor verificado nos docentes é muito fraco.

Relativamente à conflitualidade ela apresenta valores muito baixos, $0,9 \%$ para o indicador greve e é inexistente nos processos de ação disciplinar.

Para calcular o absentismo global e a taxa de presença tornou-se necessário calcular o Potencial Máximo Anual, ou seja, o número de horas que se preveem serem trabalhadas pela totalidade dos elementos da organização, com base no período normal de trabalho em vigor, fixado por lei e, que no ano em análise era de 40 horas para todos os profissionais, independentemente da categoria profissional.

A taxa de presença foi de $84,5 \%$, o que revela um absentismo de $15,5 \%$, podendo-se considerar muitíssimo elevado. $\mathrm{O}$ resultado deste indicador é um dos que nos remete para a cauda da europa em termos de produtividade. Pode considerar-se que uma organização que apresente um valor acima dos $6,5 \%$ de absentismo global, em situação de concorrência normal, estaria em risco de falência.

Não existem números rigorosos, mas calcula-se que esta taxa ronde os $6 \%$ a $8 \%$ a nível nacional, consoante os setores de atividade, considerando o conjunto de todos os setores de atividade económica do país.

Para calcular o custo médio por aluno procedemos a dois tipos de cálculo: primeiro só com os custos de funcionamento, sem incluir custos de estrutura, tais como custos de instalações e custos de gestão central (ministério, autarquia, etc.) e neste caso o valor encontrado foi de 4.069€/ano; num segundo momento, introduzimos uma percentagem para custos de estrutura em que englobamos um cálculo para custos de instalações (aquisição/renda), assim como um custo para os serviços centrais, que no caso do Ministério da Educação parecem verdadeiramente pesados, neste caso concreto, quando comparados com outros ministérios. Nesse sentido atribuímos um valor estimado de $30 \%$ como custo global de estrutura. O valor para o custo 
médio por aluno assim encontrado foi de 5.290€. Em 2009/2010 o Tribunal de Contas calculava para esse ano o valor de $4.415,45 €^{14}$. Posteriormente os custos de educação baixaram com a entrada da troika tendo havido redução dos custos de pessoal e a aumento do número de alunos por turma, enquanto as promoções de carreiras se mantiveram bloqueadas.

Considerando que uma turma é composta por 25 alunos, o custo global por turma aqui calculado foi de $110.509,6 €$. Este valor é superior em aproximadamente $45 \%$ face ao que o Ministério atribuía nesse mesmo ano aos contratos de associação com o ensino particular.

A rotação de trabalhadores é outro dos indicadores que nos ajuda a compreender a produtividade de uma organização. Quanto maior for a rotação, teoricamente menor a produtividade. Um valor de $57 \%$, como o aqui encontrado, reflete que muito dificilmente se gera uma cultura organizacional. As pessoas "vestem" em primeiro lugar a gestão da sua carreira profissional e só muito remotamente a da organização.

Vários indicadores embora podendo ter relevância, ficam sem leitura neste relatório por dificuldades de comparação inter-organizacional e longitudinal. Por maioria de razão, os indicadores relativos à eficácia e a produtividade que respeitem ao corpo discente, apenas poderão vir a ser tratados em sede de um relatório específico que excede os propósitos e a metodologia de um Balanço Social.

\section{CONCLUSÃO}

Três ideias são possíveis de extrair deste trabalho:

- Contribuir para se poder equacionar uma proposta para a criação de uma base de indicadores no setor da educação, a nível nacional, que permita a comparação entre todos os estabelecimentos escolares, não apenas os públicos, mas inclusive comparações entre públicos e privados.

- Com a descentralização de competências na educação, passando para as autarquias uma parte substancial da gestão, este instrumento poderá vir a dar a estas um verdadeiro "tableau" de bordo, abrindo espaço a uma gestão moderna, seja ela de tipo gestão tática, estratégica e política de recursos humanos, mas também uma gestão administrativa no que respeita aos quadros técnicos, outros funcionários e auxiliares de educação.

- A lei da Autonomia, com a criação do Conselho Geral, apenas no papel parece atribuir importância à comunidade educativa (as autarquias, representantes de pais, associações económicas, culturais e sociais). $\mathrm{O}$ mesmo se poderia dizer da gestão dos agrupamentos, pois só no papel é que

${ }^{14}$ Tribunal de Contas: Apuramento do Custo Médio Por Aluno, $2^{\mathrm{a}}$ Secção, Relatório N. ${ }^{\circ} 31 / 2012$, Proc. $^{\circ}$ n. ${ }^{\circ}$ 39/2011 


\section{Albino Lopes, Luís Barrosa, Amélia Virgínia Fonseca e José Manuel Machado}

é dada importância à gestão. Na prática ela é centralizada em todos os domínios, à exceção da formação, estando sub-geridas em todas as outras. Na prática é o Ministério da Educação que define todos os parâmetros da gestão corrente.

\section{BIBLIOGRAFIA}

Carvalho, J.E (1990). O Balanço Social da Empresa: uma abordagem sistémica, Lisboa, Editorial Minerva;

Carvalho, J.E (1996). Análise do Valor Económico-Laboral nas Organizações Empresariais: processo de "Rating Social", Tese de Doutoramento, Lisboa, ISCTE;

Galdemar, V., Gilles, L. et Simon, M. - O. (2012). Performance, efficacité, efficience: les critères d'évaluation des politiques sociales sont-ils pertinents? Cahiers du CREDOC, décembre;

Lopes, A. (2012). Fundamentos da Gestão de Pessoas: para uma síntese epistemológica da iniciativa da competição e da cooperação Edições Sílabo, Lisboa;

Lopes, A. e Barrosa, L. (2008). A Comunidade Educativa e a Gestão Escolar- Um Contributo da Gestão Estratégica de Recursos Humanos, Edições Pedago, Mangualde;

Lopes, A. e Barrosa, L. (2010). A escola pública portuguesa: entre a burocracia, a gestão pela qualidade e a política de autonomia contradições e tendências relativas à figura do Diretor in VI Simpósio sobre Organização e Gestão Escolar, A emergência do diretor da escola: questões políticas e organizacionais, Universidade de Aveiro;

McKinsey \& Company (2015). Contribuer au diagnostic du système scolaire en FWB. Rapport à la Vice-Présidente, Ministre de l'Education, de la Culture et de l'Enfance - Rapport à la Vice-Présidente, Ministre de l'Education, de la Culture et de L'Enfance;

Vargo, S. L. e Lusch, R. F. (2004). Envolving to a New Dominant Logic for Marketing. Journal of Marketing, (68);

Vargo, S.L. e Lusch, R. F. (2008). Service - dominant Logic: continuing the evolution. Journal of the Academy Marketing Science, (36). 